\title{
Impact of genetic counselling after neonatal screening for Duchenne muscular dystrophy
}

\author{
E Hildes, H K Jacobs, A Cameron, S S Seshia, F Booth, J A Evans, K Wrogemann, \\ C R Greenberg
}

\begin{abstract}
In a pilot neonatal screening programme for Duchenne muscular dystrophy (DMD) conducted in the Canadian province of Manitoba, a cohort of eight affected males was identified between 1 January 1986 and 31 December 1989. Demographic information, knowledge of DMD, reproductive outcome, and attitudes to prenatal diagnosis and neonatal screening for DMD were obtained through questionnaires distributed in May 1992 to the eight sets of parents of index cases, two high probability carrier aunts, and one high probability carrier sister. Personal interviews were subsequently conducted in the summer of 1992 .

Although there is overall consensus among the families in favour of routine neonatal screening for DMD, five of seven subsequent pregnancies reported in six women were not monitored by prenatal diagnosis and have resulted in the birth of two affected boys. In a comparable time interval, prenatal diagnosis was acceptable to carrier females whose affected male relatives were traditionally diagnosed at four or five years. We conclude that, although molecular genetic analysis now allows for precise diagnosis of DMD, highly accurate carrier testing and prenatal diagnosis, very early DMD carrier identification, and genetic counselling after the identification of DMD males in a population based neonatal screening programme may not be an effective way of decreasing the number of repeat cases of DMD within families or the overall population frequency of DMD.

(f Med Genet 1993;30:670-4)
\end{abstract}

Neonatal screening for Duchenne muscular dystrophy (DMD) has been in place in the province of Manitoba, Canada as a pilot programme since 1 January 1986. Acceptable criteria for introducing neonatal screening for a genetic disorder include medical intervention for the benefit of the proband or early reproductive counselling. ${ }^{1}$ In $\mathrm{DMD}$, although trials evaluating different experimental therapies are in progress, there is currently no effective therapy available. The strength of neonatal screening for DMD at this time therefore rests on very early identification of presymptomatic affected infant males leading to early carrier identification and genetic counselling with the potential to prevent the birth of additional affected children. One measure of a successful neonatal screening programme for DMD is prevention of additional affected boys in ascertained families. This paper summarises the reproductive outcome after genetic counselling in the first eight families ascertained between 1 January 1986 and 31 December 1989 on our pilot DMD neonatal screening programme.

\section{Methods}

The details of our screening programme have been published elsewhere..$^{2-4}$ Briefly, creatine kinase $(\mathrm{CK})$ activity is measured in filter paper blood spots collected as part of the routine Manitoba neonatal screening programme. If the initial screen is abnormal, the family doctor is contacted after the child is 6 weeks of age. A repeat filter paper sample is requested and assayed if informed consent is obtained by the family doctor. If a persistently raised CKMM activity is detected, the child is seen by a team of specialists for confirmatory testing and family investigations. A venous $\mathrm{CK}$ activity is measured, muscle ultrasound and muscle biopsy are performed, and molecular studies are initiated in the immediate and extended families. Systematic neurological and genetic follow up assessments by a multidisciplinary team are coordinated every six months and genetic counselling is offered to all family members, both identified carriers and noncarriers. To date, comprehensive genetic counselling has been provided by one person (CRG) to all mothers and fathers of probands and to all high risk subjects except three maternal aunts, one of whom was counselled in another genetic centre and the other two who have declined genetic counselling. Genetic counselling included repeated explanations of the genetics of DMD and the natural history of the disorder, personal communication to the families about carrier estimation and risk to subsequent male children, and detailed information about prenatal diagnosis options, including chorionic villus sampling or amniocentesis and molecular testing in all subsequent pregnancies. All families were referred to the local Muscular Dystrophy Association chapter. In May 1992 questionnaires designed to obtain demographic information, including socioeconomic status, religion, maternal age at diagnosis, further reproductive outcome, and attitudes to prenatal diagnosis and the neonatal screening programme for DMD, were sent to a total of 17 subjects older than 18 years who had received genetic counselling. Separate questionnaires were sent to both parents (if available) of the eight affected children, to two high 
risk maternal aunts, and one sister. The other high risk subjects had repeatedly declined counselling, were lost to follow up, or were below the age of consent. If not returned, the same questionnaire was sent out again four to six weeks later. Telephone follow up by a physician (EH) who had not had previous contact with the families ensured clarification of ambiguous answers and obtained direct feedback about the programme. In one family where the parent neither returned the questionnaire nor could be contacted by telephone, demographic information and personal attitudes were collated from records from follow up visits to the genetic clinic and information on reproductive outcome was obtained from other physicians who had cared for her.

\section{Results}

In Manitoba eight probands with DMD were identified initially in our neonatal screening programme for DMD between 1986 and 1989 from a screened population of 36000 male neonates. Seven were the first affected males in their families and in one family a maternal uncle of the proband had died from DMD. The pedigrees and the results of the genetic investigations in the families including molecular and dystrophin findings have been previously published. ${ }^{45}$ Briefly, five of the eight mothers of the probands were identified by pedigree, $\mathrm{CK}$, and molecular analysis as being either obligate or very high probability $(>95 \%)$ carriers. Three of eight mothers were classified as very low probability $(<5 \%)$ carriers. In addition, to date, four maternal aunts, two sisters, and one female cousin have been identified as high probability carriers. Six maternal aunts and four sisters have been counselled as being low probability carriers. The questionnaires were sent to a total of 17 subjects (see Methods) and 15 of the 17 questionnaires $(88 \%)$ were returned from seven mothers, five fathers, two aunts, and one sister. Given the lower response rate from the fathers and their less complete responses, the data presented reflect the responses of 11 females, including one who had not completed the formal questionnaire but who was interviewed.

The demographic characteristics of the 11 females from the eight families identified through the neonatal screening programme for DMD are summarised in table 1 including maternal age at the time of diagnosis of the affected child, current marital status, ethnic group, rural $v$ urban residence, religion, number of previous children, and social class based on the widely used Hollingshead scale. ${ }^{6}$ This scale of social class is based on the education and occupation of the head of the household. Both of these factors are given a numerical assignment and are weighted. There is a numerical range for each of five different social classes with class $I$ as the highest and class $V$ as the lowest.

Six of the 11 women or their partners had undergone voluntary sterilisation and in four of these six cases this decision was made before or independently of genetic counselling based on previous perceptions of ideal family size and maternal age. For one of the latter respondents, the diagnosis of DMD in her last child resulted in her desire for further children but no steps have been taken towards reversal of the surgical procedure to date. Therefore, in seven of the 11 respondents early genetic counselling provided after neonatal DMD screening had the potential to prevent additional affected children.

Reproductive outcome after the diagnosis of DMD in the proband is presented in table 2. There have been seven subsequent pregnancies reported in six women. Six of these seven pregnancies occurred in women identified and counselled as being high risk carriers. Prenatal diagnostic studies were performed in only two of these seven pregnancies. Both of these fetuses were identified as female. One pregnancy (NB-E) continued to term while the second (NB-Hi) ended in a spontaneous miscarriage two weeks after the procedure. In the remaining five pregnancies, two apparently healthy liveborn males (NB-E and NB-F) were subsequently identified by the screening programme and with confirmatory $\mathrm{CK}$ testing (CK 10000 to $15000 \mathrm{U} / \mathrm{l}$, normal $<225 \mathrm{U} / \mathrm{l}$ ) diagnosed to be affected with DMD, two healthy females (NB-B and NB-H) whose carrier status is, as yet, unknown were born, and the outcome of one pregnancy (NB-G) in the one low risk mother resulted in the birth of an unaffected male.

Reproductive attitudes towards prenatal diagnosis and termination of a pregnancy with an affected fetus are summarised in table 3 . Of the nine subjects who responded to this question, six favoured prenatal diagnosis, two were

Table 1 Characteristics of the families of the index cases of newborn DMD.

\begin{tabular}{|c|c|c|c|c|c|c|c|}
\hline Code* & $\begin{array}{c}\text { Maternal age } \\
\text { at diagnosis }(y)\end{array}$ & $\begin{array}{c}\text { Current } \\
\text { marital status }\end{array}$ & $\begin{array}{l}\text { Ethnic } \\
\text { group }\end{array}$ & $\begin{array}{c}\text { Rural } v \\
\text { urban }\end{array}$ & Religion & $\begin{array}{l}\text { Hollingshead } \\
\text { scale }\end{array}$ & $\begin{array}{l}\text { No of previous } \\
\text { children }\end{array}$ \\
\hline NB-A & 35 & $\mathbf{M}$ & Caucasian & $\mathrm{U}$ & $\operatorname{Pr}$ & IV & $1 \mathrm{~F}$ \\
\hline NB-B & 35 & M & E Indian & $\mathrm{U}$ & Sk & $\mathrm{V}$ & 0 \\
\hline $\mathrm{NB}-\mathrm{C}$ & 33 & M & Caucasian & $\mathbf{R}$ & Not specified & III & $2 \mathrm{~F}$ \\
\hline NB-D & 29 & M & Caucasian & $\mathrm{U}$ & Not specified & III & $2 \mathrm{M}$ \\
\hline NB-E & 28 & $\mathrm{CL}$ & Aboriginal & $\mathrm{U}$ & Not specified & V & $2 \mathrm{~F} 1 \mathrm{M}$ \\
\hline NB-F & 32 & $\mathbf{M}+$ & Caucasian & $\mathbf{R}$ & C & IV & $3 \mathrm{~F}$ \\
\hline NB-Fi & 15 & $\mathrm{~s}$ & Caucasian & $\mathbf{R}$ & C & IV & 0 \\
\hline NB-G & 22 & $\mathbf{M}$ & Caucasian & $\mathbf{R}$ & C & IV & 0 \\
\hline NB-H & 20 & $\mathrm{~s}$ & $\begin{array}{l}\text { Caucasian/ } \\
\text { W Indian }\end{array}$ & $\mathrm{U}$ & C & IV & $1 \mathrm{~F}$ \\
\hline NB-Hi & 22 & D & Caucasian/ & $\mathrm{U}$ & C & IV & $1 \mathrm{~F}$ \\
\hline NB-Hii & 23 & D & $\begin{array}{l}\text { Caucasian/ } \\
\text { W Indian }\end{array}$ & $\mathrm{U}$ & C & III & 0 \\
\hline
\end{tabular}

$S k=$ Sikh. $\operatorname{Pr}=$ Protestant. $C=$ Catholic. $M=$ married. $S=$ single. $C L=$ common law. $D=$ separated, divorced.

* Designation according to reference 5 .

+2 nd marriage, 2 daughters from previous marriage. 
Table 2 Reproductive outcome in nuclear and extended families.

\begin{tabular}{|c|c|c|c|c|c|c|c|c|}
\hline Code & $\begin{array}{l}\text { Year of birth of } \\
\text { DMD proband }\end{array}$ & $\begin{array}{l}\text { Carrier } \\
\text { probability }\end{array}$ & $\begin{array}{l}\text { Subsequent } \\
\text { pregnancy }\end{array}$ & Outcome & $\begin{array}{l}\text { Prenatal } \\
\text { diagnosis }\end{array}$ & Reason & $\begin{array}{l}\text { Clinical status of DMD } \\
\text { proband at time of pregnancy }\end{array}$ & Comment \\
\hline $\begin{array}{l}\text { NB-A } \\
\text { NB-B } \\
\text { NB-C } \\
\text { NB-D } \\
\text { NB-E }\end{array}$ & $\begin{array}{l}1986 \\
1986 \\
1986 \\
1987 \\
1988\end{array}$ & $\begin{array}{l}\mathrm{H} \\
\mathrm{H} \\
\mathrm{L} \\
\mathrm{L} \\
\mathrm{H}\end{array}$ & $\begin{array}{l}0 \\
1,1988 \\
0 \\
0 \\
2,1991 \\
\quad 1992\end{array}$ & $\begin{array}{l}\text { F } \\
\underset{\mathrm{F}}{\mathrm{M}} \mathrm{DMD}\end{array}$ & $\begin{array}{l}\text { NO } \\
\text { NO } \\
\text { Yes, 46,XX } \\
\text { Amniocentesis }\end{array}$ & $\begin{array}{l}\text { D } \\
\text { LP }\end{array}$ & $\begin{array}{l}\text { NA } \\
\text { Gower- } \\
\text { NA } \\
\text { NA } \\
\text { Gower+ } \\
\text { Gower+, DD }\end{array}$ & $\begin{array}{l}\text { V } 1986 \\
\text { TL } 1989 \\
\text { V } 1986 \\
\text { TL } 1987\end{array}$ \\
\hline $\begin{array}{l}\text { NB-F } \\
\text { NB-Fi } \\
\text { NB-G } \\
\text { NB-H } \\
\text { NB-Hi } \\
\text { NB-Hii }\end{array}$ & $\begin{array}{l}1988 \\
1988 \\
1988 \\
1988 \\
1988 \\
1988\end{array}$ & $\begin{array}{l}\mathrm{O} \\
\mathrm{H} \\
\mathrm{L} \\
\mathrm{H} \\
\mathrm{H} \\
\mathrm{H}\end{array}$ & $\begin{array}{l}0 \\
1,1991 \\
1 \\
1,1991 \\
1,1990 \\
0\end{array}$ & $\begin{array}{l}\text { M DMD } \\
\mathrm{M}^{*} \\
\mathrm{~F} \\
\mathrm{~F}^{\dagger}\end{array}$ & $\begin{array}{l}\text { No } \\
\text { NO } \\
\text { NO } \\
\text { Yes, CVS }\end{array}$ & $\begin{array}{l}\text { LP } \\
\text { D } \\
\text { LP }\end{array}$ & $\begin{array}{l}\text { DD, delayed ambulation } \\
\text { DD, delayed ambulation } \\
\text { Gower }+ \\
\text { Gower }+ \\
\text { Gower }+ \\
\text { NA }\end{array}$ & TL 1991 \\
\hline
\end{tabular}

$\mathrm{L}=$ low $<5 \% ; \mathrm{H}=$ high $>95 \% ; \mathrm{O}=$ obligate; $\mathrm{D}=$ declined; $\mathrm{NO}=$ not offered; $\mathrm{TL}=$ tubal ligation; $\mathrm{V}=$ vasectomy; $\mathrm{LP}=$ late presentation; $\mathrm{DD}=$ developmental delay; * no deletion on genomic DNA; † spontaneous abortion 2 weeks after procedure.

Table 3 Reproductive attitudes and satisfaction with DMD Newborn Screening Programme.

\begin{tabular}{llclll}
\hline Code & $\begin{array}{l}\text { Knowledge about } \\
\text { DMD }\end{array}$ & $\begin{array}{l}\text { Correct knowledge } \\
\text { of carrier status }\end{array}$ & $\begin{array}{l}\text { Favour prenatal } \\
\text { diagnosis }\end{array}$ & $\begin{array}{l}\text { Favour pregnancy } \\
\text { termination }\end{array}$ & $\begin{array}{l}\text { Favour routine } \\
\text { newborn screening }\end{array}$ \\
\hline NB-A & Adequate & No & No & No & Yes \\
NB-B & Not specified & No & Not specified & Not specified & No \\
NB-C & Adequate & Yes & Yes & Yes & Yes \\
NB-D & Adequate & Yes & Unsure & Unsure & Yes \\
NB-E & Not specified & Yes & Unsure & Unsure & Ynsure \\
NB-F & Adequate & No & Yes & No & Not specified \\
NB-Fi & Adequate & No & Yes & No & Yes \\
NB-G & Adequate & Yes & Unsure & Yes & Yes \\
NB-H & Adequate & Yes & Yes & Not specified & Yes \\
NB-Hi & Adequate & Yes & Yes & & \\
NB-Hii & Adequate & No & Yes & & \\
\hline
\end{tabular}

unsure, and one was opposed to prenatal diagnosis. This compares with three of seven who stated that they would terminate a pregnancy with an affected fetus, three who would definitely not terminate such a pregnancy, and one who was unsure. Overall knowledge of DMD was adequate. Nine of nine responders knew it was a fatal disease causing progressive weakness of the muscles, that DMD was a genetic disorder and therefore heritable, and that only males were affected while females could be carriers. However, only seven out of 11 had correct recall of their own carrier status. When asked if newborn screening for DMD should be routine, the response was clearly positive with eight out of 10 responders being in favour of routine neonatal screening for DMD.

\section{Discussion}

The majority of the parents of the eight original males identified by the newborn DMD screening programme in Manitoba were white $(75 \%)$, married $(75 \%)$, and living in an urban setting $(62.5 \%)$ reflecting the demography of the population of Manitoba. Five of the 12 women identified to date as being high risk carriers had had a total of 12 healthy children (nine female, three male) before the birth of the affected son in their family whereas the three low risk mothers of probands had had four previous children (two female, two male). ${ }^{5}$ In only two families was the affected boy the first born child. This previous reproductive history combined with an older mean maternal age and recent sterilisation have probably had an impact on the reproductive decision making and outcome in our study families.

The aspect of reproductive outcome that was perhaps the most remarkable given the comprehensive genetic counselling received was the number of unmonitored pregnancies (five out of seven). Four of five of these unmonitored pregnancies were in high risk carrier mothers and resulted in the birth of two affected males. Looking at the individual situations involved, three of the unmonitored pregnancies were unplanned and the mothers presented for antenatal care at approximately 20 to 22 weeks' gestation. NB-E's first pregnancy after the birth of her affected son was unanticipated and the product of a relationship with a different father from that of her previous four children. The two daughters from her first common law relationship had died in a house fire approximately six months after the diagnosis of DMD was made in her son. Another male child was identified as affected with DMD soon after birth. A second subsequent pregnancy was monitored by amniocentesis and has resulted in the birth of a healthy female. NB-Fi was a single teenager living at home with her parents. She did not seek medical care until approximately 5 months' gestational age. Her high risk carrier status was discussed with her and her mother when she was 16 years of age. An affected male was subsequently diagnosed after birth. NB-H's pregnancy resulted from a contraceptive failure surrounded by social chaos with the biological father threatening to abandon her if the child was not relinquished for adoption. The subsequent pregnancy of NB-B, a high risk carrier mother, was planned and prenatal diagnosis was requested. However, a scheduled appointment for CVS was cancelled at the last minute and since that time the family cannot be contacted by phone, but the parents did respond to the mailed out questionnaires. The subsequent birth of a healthy female child was confirmed by the family doctor. This family has declined follow up for their affected child by the DMD interdisciplinary team and we have learned that the child is currently living 
with grandparents in another country. The fifth unmonitored pregnancy is in a woman with a low risk of being a DMD carrier based on molecular analysis of a gene deletion. ${ }^{5}$ She was offered CVS and understood the possibility of undetected gonadal mosaicism but declined prenatal testing primarily because, as seen in table 3, termination of an affected pregnancy would not be considered. A male child has been born and is considered not to be affected with DMD on the basis of a normal CK level and the absence of any detectable molecular alteration in the dystrophin gene. Overall, the amount of social chaos in the lives of the four high risk women who did not request prenatal diagnosis seems disproportionately high for our small number of index families, but does seem to correspond to their lower Hollingshead social class reflecting education and occupation. The socially disrupted lives of these women appear to be one important factor in their reproductive decision making.

Of importance to note are the relatively mild clinical signs in the affected males at the time of the mother's subsequent pregnancy. At the time of subsequent pregnancy, three affected males had a positive Gower sign and two children had shown delayed motor milestones but were Gower sign negative. Two, however, were globally developmentally delayed. The paucity of striking clinical symptoms in the majority of very young affected males ascertained by newborn screening as opposed to the time of traditional diagnosis at 4 or 5 years of age may also contribute towards denial of the diagnosis and affect the decision to reproduce further or to continue with a pregnancy once conceived without prenatal diagnosis. This reluctance to terminate an affected pregnancy is seen in other disorders where there is no associated mental retardation and lifespans extend beyond early childhood. ${ }^{7}$ The complex psychology behind the decision to request termination of an affected pregnancy while still caring for and loving an affected but apparently healthy child showing mild symptoms, if any, cannot be ignored. The uncertainty as to whether to seek prenatal diagnosis and request termination of an affected pregnancy seems to be less in single gene disorders where gross developmental delay or handicap is apparent from infancy and therefore evident to the parents at the time of subsequent pregnancy. ${ }^{89} \mathrm{As}$ well, in our experience, prenatal diagnosis and termination of pregnancy requests are acceptable to high risk DMD carriers identified after traditional clinical diagnosis of DMD in their families in that four requests for early prenatal diagnosis in this same time period have been made by such mothers. However, as appropriate comparative data are not available, we are uncertain at present if acceptance of prenatal diagnosis in our population is greater among mothers and female relatives of traditionally diagnosed DMD patients.

With the small number of study families at present it is difficult or impossible to assess the impact of genetic counselling on reproductive choice outcome. This is especially true since in four out of 11 respondents a decision towards limiting family size by permanent sterilisation of one member of the couple had already been made before counselling. All of these decisions seemed largely based on both maternal age and number of previous children. After counselling, a further two out of the 11 women underwent permanent sterilisation. In both cases sterilisation followed subsequent pregnancies. However, in these two instances we feel genetic counselling may have had substantial impact leading towards sterilisation. Only as our sample size grows to include younger women at the beginning of their reproductive years may the impact of genetic counselling be maximally apparent.

Finally, as seen in table 3, all but one of the parties involved felt that the Newborn Screening Programme was helpful and should be introduced as part of routine neonatal screening in this province. The comments supporting these viewpoints were generally that early diagnosis had helped the family prepare for and cope with the physical changes now occurring in affected boys and allowed them to be linked early on with counselling, rehabilitation services, and parent support groups. Three respondents mentioned that early diagnosis may have an impact on further reproductive choice but two of these three respondents were permanently sterilised before genetic counselling. Thus, this statement did not apply directly to themselves. In spite of an overall positive response to routine newborn screening, actual personal satisfaction with the programme involving all the different members of the diagnostic and follow up team were more varied, ranging from enthusiastic endorsement to disappointment. In many cases this reflects denial or difficulty in accepting and coping with the diagnosis of DMD in the preclinical years. In part, the parents may have felt some uncertainty as this is a pilot programme, itself in its infancy.

In summary, six of 11 women who responded to our questionnaire and from whom medical/personal information is available have had pregnancies after the diagnosis of a male affected with DMD in their family. Only two of these seven pregnancies were monitored by prenatal diagnosis. Two affected males were born and subsequently diagnosed as DMD. The only published data on reproductive outcome in other pilot neonatal screening programmes currently under way in North America and Europe is from the group in Lyons, France. The latter investigators with long standing experience in neonatal screening for DMD have not reported an experience similar to ours. ${ }^{10}$ Although the very small numbers involved in our study may not accurately reflect the potential impact of genetic counselling on reproductive choice, the tacitly held assumption that early carrier diagnosis will necessarily decrease the number of subsequently affected children, at least in our population, seems premature as it oversimplifies the complex decision of reproductive choice. To this end, newly identified families will con- 
tinue to be counselled and followed for data collection.

The aim of newborn screening is to reduce the burden of DMD in families. By early identification of affected males leading to very early identification and genetic counselling of carrier females, the birth of repeated affected boys within families may be prevented. Although this aim has yet to be realised, based on the early results of reproductive outcome, the additional positive benefits of neonatal screening in terms of family adjustment, informed reproductive choice, and in the future early therapy for affected children may make neonatal screening for DMD a beneficial endeavour from many different perspectives.

We wish to acknowledge the cooperation and interest of all the families involved and their physicians. The invaluable assistance of Wendy Stoeber, RN, MA, and the advice of Dr M Moffatt is also gratefully acknowledged. This work was supported by the Muscular Dystrophy Association of Canada and the Children's Hospital of Winnipeg Research Foundation.
1 Laberge CM, Knoppers BM. Workshop on genetic screening: from newborns to DNA typing. In: Laberge CM, Knoppers BM, eds. Genetic screening from newborns to DNA typing. Amsterdam: Elsevier, 1990:379-90.

2 Jacobs HK, Cameron AI. A pilot program of screening for acobs HK, Cameron AI. A pilot program of screening for Duchenne muscular dystrophy in the Canadian province
of Manitoba. In: Therrell TL Jr, ed. Advances in neonatal of Manitoba. In: Therrell TL Jr, ed. Advances in
screening. Amsterdam: Elsevier, 1987:367-70.

3 Jacreening. Amsterdam: Elsevier, 1987:367-70. Cameron AI. Neonatal screening for Duchenne muscular dystrophy - the Canadian experience. In: Schmidt BJ, Diamont AJ, Loghin-Grosso NS, eds. Current trends in infant screening. Amsterdam: Elsevier, 1989:361-6.

4 Greenberg CR, Rohringer $M$, Jacobs HK, et al. Gene studies in newborn males with Duchenne muscular dystrophy detected by a neonatal screening programme. Lancet 1988;ii:425-7.

5 Greenberg CR, Jacobs HK, Halliday W, Wrogemann K. Three years' experience with neonatal screening for Duchenne/Becker muscular dystrophy: gene analysis, gene expression and phenotype prediction. $A m \mathcal{F}$ Med Genet 1991;39:68-75.

6 Hollingshead AB. Two factor index of social position. 1965 Yale Station, New Haven, CT, 1957.

7 Wertz DC, James SR, Rosenfield JM, Erbe RW. Attitudes toward prenatal diagnosis of CF: factors in decision making among affected families. Am $\mathcal{J}$ Hum Genet making among

8 Turner G, Robinson H, Laing S, et al. Population screening for fragile X. Lancet 1992;339:1210-13.

9 Kaback MM, Nathan TJ, Greenwald S. Tay Sachs disease: heterozygote screening and prenatal diagnosis - U.S experience and world perspective. In: Kaback MM, ed. Tay-Sachs disease: screening and prevention. New York: Alan R Liss, 1977.

10 Plauchu H, Cordier MP, Carrier HN, et al. Systemic neonatal detection of Duchenne's muscular dystrophy. Results after 10 years of experience in Lyons (France). $\mathcal{f}$ Genet Hum 1987;35:217-30. 